\title{
Epstein Barr Virus in childhood and adolescent classical Hodgkin lymphoma in a French cohort of 301 patients
} \author{
and Judith Landman-Parker ${ }^{11}$ \\ ${ }^{1}$ Centre Hospitalier Universitaire de Besançon \\ ${ }^{2}$ Armand-Trousseau Childrens Hospital \\ ${ }^{3}$ Hospital Andre Mignot \\ ${ }^{4}$ Assistance Publique - Hôpitaux de Paris \\ ${ }^{5}$ Gustave Roussy \\ ${ }^{6}$ Curie Institute Hospital Group \\ ${ }^{7}$ Hospices Civils de Lyon \\ ${ }^{8}$ Jeanne de Flandre Hospital \\ ${ }^{9}$ Hospital Timone \\ ${ }^{10}$ University Hospital Centre Rennes \\ ${ }^{11}$ Hopital Armand-Trousseau
}

Victor Pereira ${ }^{1}$, Sabah Boudjemaa ${ }^{2}$, Caroline Besson $^{3}$, Thierry Leblanc ${ }^{4}$, Charlotte Rigaud $^{5}$, Amaury Leruste ${ }^{6}$, Nathalie Garnier ${ }^{7}$, Anne Lambilliotte ${ }^{8}$, Mathieu Simonin ${ }^{2}$, Catherine Curtillet $^{9}$, Jacinthe Bonneau-Lagacherie ${ }^{10}$, Aurore COULOMB L'HERMINE ${ }^{2}$,

May 25, 2021

\begin{abstract}
To analyze the role of Epstein-Barr virus (EBV) in the biological and clinical characteristics of patients treated for classic Hodgkin lymphoma (cHL) in France. Bio-pathological data of 301 patients treated for a cHL in or according to the protocol of the EuroNet PHL-C1 trial between November 2008 and February 2013 were centrally reviewed. Median age at diagnosis was 14 [3-18] years and the F/M ratio $0.86,0.47$ before 10 years and 0.9 from 11 to 18 . CHL subtypes were nodular sclerosis for 266/301 (88\%) patients, mixed cellularity for 22/301 (7\%), lymphocyte rich for 2/301 (1\%), and 11/301 were unclassified. EBV expression in situ (EBV cHL) was observed for 68/301 (23\%) patients, significantly associated with MC subtype and male gender, and there was a trend with age $<10$ years, it was particularly overrepresented in boys below 10 years: $15 / 23$ (65\%) vs 28/139 among other male patients (20\%). Event-free and overall survival were equivalent between EBV and non-EBV cHL patients. EBV viral load was tested for 108/301 patients and detectable in $22 / 108$ (22\%) cases. A positive viral load was overrepresented in EBV cHL versus non-EBV cHL patients: 13/28 (46\%) vs 9/80 (11\%). Detailed semi-quantitative histological analysis showed a high number of B-cell residual follicles in EBV cHL and no significant association with CD 20 or PAX 5 immunostaining in tumoral cells relative to EBV-negative HL. Distribution of EBV cHL in children and adolescents is associated with young age and male gender, suggesting a specific physiopathology and may require a differential therapeutic approach.
\end{abstract}

\section{Introduction}

Hodgkin lymphoma (HL) is a malignant B-cell lymphoid tumor that arise from lymph-node germinal centers, characterized by Reed-Sternberg cells (RSCs) surrounded by non-tumor polymorphic inflammatory cells [1]. The revised WHO 2008 lymphoma classification, updated in 2016 [2,3], describes two different histological types, nodular lymphocyte predominant HL and classic HL (cHL), which is further divided into four patho- 
logical subtypes: nodular sclerosis (NS), mixed cellularity (MC), lymphocyte rich (LR), and lymphocyte depleted (LD). The involvement of Epstein-Barr virus (EBV) in the pathogenesis of cHL was initially suspected because of the observation of a high level of EBV-associated antibodies in HL patients [4, 5]. Since then, viral protein expression and clonal integration of the EBV genome in RSCs have been described $[6,7]$. The presence of EBV in cHL varies from 13 to $79 \%$ depending on the series. It is associated with younger or older age ( $<10$ or $>50$ years ), lower economic status, ethnicity (Hispanic, African population) [8, 9], MC histology, and immunosuppression [10-23]. The presence of in situ EBV has been shown to have no prognostic impact except for patients $>50$ years of age [24]. Moreover, the standard therapeutic approach for HL associated with EBV (EBV cHL) does not differ from non-EBV cHL treatment. cHL in children and adolescents differs from that in adults in many ways and improved biological knowledge of this entity may allow refinement of the treatment strategy.

Children and adolescents presenting with cHL in France were included in the European trial EuroNet PHLC1 (EudraCT-No.: 2006-000995-33) from 2008 to 2013 and in an add-on biological study LH-EPI. Here, we present the combined analysis of clinical, pathological, and biological characteristics of cHL associated with in situ EBV detection.

\section{Methods}

\section{Patients}

We analyzed data from the cohort of French children and adolescents with cHL included in the EuroNet PHL-C1 trial (EudraCT-No.: 2006-000995-33) from November 2008 to February 2013. The trial design is provided in Supplemental Figure 1. The main points of this randomized trial were to replace procarbazine with dacarbazine for intermediate- and advanced-stage patients and to restrict radiotherapy to patients with an inadequate response after the first two cycles of chemotherapy. Patients were divided into three treatment groups (TG): TG1: stages IA/B and II, TG2: stages IA/B E, IIB, IIIA, and TG3: stages IIBE, IIIAE/B, and IV. All patients and families provided informed written consent according to good clinical practice and the ethical committee.

Histopathology, biology parameters, and EBV testing

A formal central histological review was performed in the department of pathology of Armand Trousseau hospital in Paris by S. B. and A. C. Paraffin-embedded tissue blocks or unstained slides were obtained at the time of diagnosis and retrieved from the local pathology centers. A conventional histological study was performed on hematoxylin-eosin-saffron (HES) stained tissue sections to confirm the HL diagnosis for each sample (percutaneous biopsy or surgical resection). This histological review included quantification of the inflammatory microenvironment: lymphocytes, histiocytes, eosinophils, neutrophils, and plasma cells. The presence of residual B follicles was also evaluated, as well as the amount of fibrosis and necrosis when present. Immunohistochemistry was performed using antibodies against the following markers: CD30 (Novocastra), CD3 (Dako ), CD20 (Agilent Dako), CD15 (Novocastra), PAX5 (Dako ), and CD68 (Agilent Dako , KP1 clone ). Sections of $3 \mu \mathrm{m}$ were cut with a microtome. Tissue sections were deparaffinized and rehydrated through a series of xylene and ethanol washes and then incubated with primary antibodies. The immunostainings were processed using a Leica Bond automated immunostaining device. EBV protein detection was performed using EBV-encoded RNA (EBER) in situ hybridization (Roche) and latent membrane protein (LMP1) histochemical staining (Agilent Dako ). To consider a HL case to be EBV-related, the EBER (nuclear) and/or LMP1 (cytoplasmic and surface membrane) signal had to be unequivocally present in ReedSternberg/Hodgkin cells. A semi-quantitative histological score based on crosses was used for interpretation (0: negative, $1+$ : weak, $2+$ : moderate, $3+$ : numerous). To better define the immunological features of the population, data from the French prospective add-on study LH-EPI were analyzed to define the peripheral B-cell characteristics associated with the clinical and pathological cHL lymphoma. Immunoglobulin G, A, and $\mathrm{M}$ quantification was performed at trial inclusion, as well as extensive lymphocyte immunophenotyping when hypogammaglobulinemia was detected. EBV serology and Viral EBV load analysis by PCR was performed as described in Hamdi et al [25] when anti-VCA IgG was detected. The viral load positivity cut-off 
was 125 copies/ml.

Statistical analysis

Age, gender, stage, treatment, and radiotherapy were analyzed. All events (deaths, relapse, secondary tumors) for patients were recorded as part of the formal follow-up. Biological and pathological data were collected via the LH-EPI and the pathological review databases, respectively. Statistical analysis was performed using the BiostaTGV application. The chi-2 test and Fisher's exact test were used to compare proportions. Survival analysis according to EBV status was performed using the Kaplan Meier method. Log rank tests were used to compare survival. Differences were considered significant for $\mathrm{p}<0.05$.

\section{Results}

Among the 386 patients enrolled in the EuroNet PHL-C1 trial in France, 301 patients were included in our study with available reference pathology review. The review was performed by another pathological network without detailed data available for 72 patients, and no samples were obtained for 13 other cases as Formal Fixed Paraffin Embedded (FFPE) blocks were exhausted. The population characteristics are presented in Table 1 . The female/male ratio was 139/162 (0.86), with a median age at diagnosis of 14 years. The distribution of TG1, TG2, and TG3 was 85/301 (28\%), 71/301 (24\%), and 145/301 (48\%) patients, respectively. There was no significant association between repartition of the treatment groups and B symptoms or EBV status of the RSCs.

Histopathology

The pathological characteristics of the samples are presented in Table 2. Among the 301 cases, the predominant subtype was nodular sclerosis (NS), representing $88 \%$ of cases $(266 / 301)$. The other subtypes were mixed cellularity (MC), representing $7 \%$ of cases (22/301) and lymphocyte rich, representing i 1\% (2/301). There were no case of lymphocyte-depleted cHL. Eleven cases remained unclassified due to the small size of the samples (fine-needle biopsies), with no proper evaluation of the background architecture. EBV in situ expression was observed in tumor cells in $23 \%$ of cases $(68 / 301)$.

Clinical characteristics

Being $<10$ years of age was more frequent for EBV cHL $(17 / 68,25 \%)$ than non-EBV cHL $(17 / 233,7 \%)$ $(\mathrm{p}<0.001)$. Male gender tended to be more frequent in the EBV cHL (F/M ratio: 0.58) than non-EBV cHL population $(\mathrm{F} / \mathrm{M}$ ratio: 0.96$)(\mathrm{p}=0.07)$. EBV cHL was overrepresented in boys $<10$ years of age, $15 / 23(65 \%)$ versus 28/139 $(20 \%)$ for boys [?] 10 years of age $(\mathrm{p}<0.01)$. Five-year overall survival (OS) and event-free survival (EFS) were $99 \%$ and $89 \%$, respectively, for the 301 patients, with a median follow-up of 54 months. There were no significant differences in either OS or EFS between the EBV-positive and EBV-negative populations ( $\mathrm{p}=0.35$ and $\mathrm{p}=0.91$, respectively) (Fig. 2 and 3 ); 2/301 patients died during the 54 months of follow-up, one with EBV cHL and one with non-EBV cHL. Thirty-four of the 301 patients experienced a relapse: 27 non-EBV cHL and 7 EBV cHL.

MC cHL was more highly represented among EBV cHL $(15 / 68,22 \%)$ than non-EBV cHL patients $(7 / 233$, $3 \%)(\mathrm{p}<0.001)$. In addition, 54/68 (79\%) EBV cHL samples had residual B follicles versus 121/233 (52\%) for non-EBV cHL samples ( $<$ 0.001) (Fig. 1). No significant correlation was observed between EBV status and T-lymphocytic infiltrate or the presence of necrosis. The microenvironment was generally polymorphic, with a granulomatous infiltrate, associating eosinophils and histiocytes, without a significant difference in composition: presence or not of lymphocytes, eosinophils, histiocytes, or neutrophils. Immunophenotyping showed the expression of CD30 in 301 (100\%) cases, CD15, in $243(81 \%)$, PAX5 in $212(70 \%)$, and CD20 in $62(21 \%)$. RSCs showed no significant differences in staging, the presence of necrosis, the expression of CD15, PAX5, or CD20, or EBV positivity (Table 3).

\section{Blood EBV data}

Immunological analysis was performed throughout LH EPI study [25]. Samples from a subgroup of 108/301 patients were tested for EBV viral load by PCR. Viral EBV load was detectable for 22 (20\%) patients with 
a median value of 1,680 copies/ml [130-3638]. Among the same 108 patients, 28 (26\%) had EBV cHL. The median viral load of EBV cHL patients $(\mathrm{n}=13 / 28)$ was 2,042 copies $/ \mathrm{ml}[198-30638]$ versus $1,348 \mathrm{copies} / \mathrm{ml}$ [130-18190] for non-EBV cHL $(\mathrm{n}=9 / 80)(\mathrm{p}<0.001)$. Only 23/68 patients with EBV cHL had available EBV serology; among them two had IgM (recent EBV infection profile) and 22 anti EBNA or VCA IgG.

\section{Discussion}

We analyzed the clinical, biological, and pathological characteristics of a pediatric cohort with EBV cHL. The EBV positivity rate in tumor cells was $23 \%$. This result is in the range of reported positivity in European countries $[13,18,21,26]$. EBV positivity varies depending on geographic area and ethnicity: $17 \%$ in the Czech Republic, $79 \%$ in Kenya, $78 \%$ in India, $52 \%$ in Zambia, and $46 \%$ in Jordan [10, 11, 17, 18, 21, 27]. The EBV rate in cHL has been evolving over time. Takeuchi et al. [28] reported a decreasing rate of EBV in cHL, irrespective of age, histological subtype, or ethnicity. These data were confirmed by Campos et al. [29], who reported that the $\mathrm{EBV}^{-} / \mathrm{EBV}^{+}$ratio for Brazilian patients under 15 years of age decreased from 6.5 in 1954 to 0.8 in 2008. Most studies have described a bimodal distribution of EBV in tumor cells according to age $[17,20,26,30]$. In our cohort, the female/male ratio was 0.86 and decreased to 0.47 for children [?] 10 years of age. The male gender was more highly represented among young patients, as already described by Clavel et al. [31]. In our population, children $<10$ years of age had a significantly higher proportion of EBV-associated disease than children $>11$ : $50 \%$ of cases versus $19.2 \%(\mathrm{p}<0.001)$. This difference can be explained by the age-dependent defect of the control of primary EBV infection and strengthens the argument that the physiopathology of cHL in younger children is probably different from that in older patients, particularly concerning the immune response to EBV in boys. This hypothesis has already been proposed in previous studies $[32,33]$ and the potential involvement of differences in the control of EBV infection in the pathogenesis of cHL merits further study. Genomics studies to detect specific genetic variants among children will be the next step to improve our knowledge about the predisposition to EBV cHL. There was a significant predominance of the MC subtype for EBV cHL in the French cohort $(22 \%$ for EBV cHL versus $3 \%$ for non-EBV cHL, $\mathrm{p}<0.001$ ). This association has been consistently highlighted in various international cohorts and has persisted over time [16, 29], although changes in the repartition of cHL histological subtypes to the benefit of NS cHL has been described $[17,34,35]$. Our study confirms this trend, with $88 \%$ NS cHL and 7\% MC whereas the values were $70 \%$ and $20 \%$, respectively, in a French cohort of cHL published 20 years ago [35].

In our study, the presence of residual B follicles was significantly associated with EBV in-situ positivity (79\% for EBV cHL vs $52 \%$ for non-EBV cHL, p < 0.001), raising questions about the role of the B-cell environment in the survival of $\mathrm{EBV}^{+} \mathrm{RSCs}[25,36]$. Of interest, the LH EPI study showed an association between Bcell lymphopenia and non-EBV cHL. Recently, several reports [11] have re-evaluated the involvement of EBV in the immune response to cHL. Carbone et al. showed the LMP-1 oncoprotein to be primordial in oncogenesis, leading to aberrant activation of oncogenic signaling pathways and increased PD-L1 expression, thus suppressing the cytotoxic T-cell anti-tumoral response and allowing unchecked tumoral development. [37]. Moreover, EBV RSCs appear to escape immune control via different pathways than EBV-negative cells harboring fewer somatic mutations in NFxb/proapoptotic genes, as well as less 9p24.1 amplification and fewer chromosomal breakpoints, [38] with higher PD-L1 expression in EBV cHL than non-EBV cHL, as already mentioned [39]. Thus, we can hypothesis that EBV infection induces PD-L1 expression in the tumor microenvironment via proinflammatory cytokines, leading to a different physiopathology depending on the EBV status and, therefore, age. These bio-pathological events raise interesting therapeutic issues, suggesting a place for checkpoint inhibitors, which could represent the future of EBV cHL treatment, combined with conventional therapies (radio chemotherapy) or associated with anti-EBV therapies [40]. Our data confirm the significant predominance of mixed cellularity subtypes, young age, male gender, elevated viral load, and the presence of residual B-cells in EBV-positive cHL, thus paving the way to better defining the role of EBV in the pathogenesis of Hodgkin lymphoma in children and serving as a starting point for future studies.

\section{Conflict of interest statement}

The authors have no potential conflicts of interest to report. 


\section{Acknowledgements}

We would like to thank Elodie Drouet, Emmanuelle Vié, and Christiane Vitali for help in data collection.

\section{Funding}

111 des Arts : N08-73-08 and SFCE/ Enfant et Santé AO 2011

Data sharing statement

\section{Research data are not shared}

\section{References}

1. Eberle FC, Mani H, Jaffe ES. Histopathology of Hodgkin's Lymphoma: The Cancer Journal , 2009 15: $129-137$.

2. Swerdlow SH, Campo E, Pileri SA, Harris NL, Stein H, Siebert R, Advani R, Ghielmini M, Salles GA, Zelenetz AD, Jaffe ES. The 2016 revision of the World Health Organization classification of lymphoid neoplasms. Blood , 2016 127: 2375-2390.

3. Swerdlow S, Campo E, Harris N. WHO Classification of Tumours of Haematopoietic and Lymphoid Tissues. International Agency for Research on Cancer , 2008.

4. Mueller N. Epidemiologic studies assessing the role of the Epstein-Barr virus in Hodgkin's disease. Yale J Biol Med , 1987 60: 321-332.

5. Evans AS, Gutensohn NM. A population-based case-control study of EBV and other viral antibodies among persons with Hodgkin's disease and their siblings. Int J Cancer , 1984 34: 149-157.

6. Kanavaros P, Jiwa M, van der Valk P, Walboomers J, Horstman A, Meijer CJLM. Expression of EpsteinBarr virus latent gene products and related cellular activation and adhesion molecules in Hodgkin's disease and non-Hodgkin's lymphomas arising in patients without overt pre-existing immunodeficiency. Human Pathology , 1993 24: 725-729.

7. Khan G, Naase MA. Down-regulation of Epstein-Barr virus nuclear antigen 1 in Reed-Sternberg cells of Hodgkin's disease. J Clin Pathol , 1995 48: 845-848.

8. Weinreb M, Day PJ, Niggli F, Powell JE, Raafat F, Hesseling PB, Schneider JW, Hartley PS, TzortzatouStathopoulou F, Khalek ER, Mangoud A, El-Safy UR, Madanat F, Al Sheyyab M, Mpofu C, Revesz T, Rafii R, Tiedemann K, Waters KD, Barrantes JC, Nyongo A, Riyat MS, Mann JR. The role of Epstein-Barr virus in Hodgkin's disease from different geographical areas. Arch Dis Child , 1996 74: 27-31.

9. Jarrett AF, Armstrong AA, Alexander E. Epidemiology of EBV and Hodgkin's lymphoma. Annals of Oncology, 1996 7: S5-S10.

10. Kafita D, Kaile T, Malyangu E, Tembo R, Zulu E, Chisanga C, Kalonda A, Samutela M, Polepole P, Kwenda G. Evidence of EBV infection in lymphomas diagnosed in Lusaka, Zambia. Pan Afr Med J , 2018 29.

11. Murray PG, Young LS. An etiological role for the Epstein-Barr virus in the pathogenesis of classical Hodgkin lymphoma. Blood , 2019 134: 591-596.

12. Toriyama K, Itakura H, Kamidigo NO, Kusuda M. A comparison of epidemiologic, histologic, and virologic studies on Hodgkin's disease in western Kenya and Nagasaki, Japan. The American Journal of Tropical Medicine and Hygiene, 1998 59: 801-807.

13. Association between EBV and HL in Belgium a pathological and virological study.pdf 
14. Barros MHM, Hassan R, Niedobitek G. Disease patterns in pediatric classical Hodgkin lymphoma: a report from a developing area in Brazil. Hematological Oncology , 2011 29: 190-195.

15. Meng J, Chang C, Pan H, Zhu F, Xiao Y, Liu T, Nie X, Wu G, Zhang L. Epidemiologic characteristics of malignant lymphoma in Hubei, China: A single-center 5-year retrospective study. Medicine, 2018 97: e12120.

16. Huang X, Nolte I, Gao Z, Vos H, Hepkema B, Poppema S, van den Berg A, Diepstra A. Epidemiology of Classical Hodgkin Lymphoma and Its Association with Epstein Barr Virus in Northern China. PLoS ONE , 2011 6: e21152.

17. Sughayer MA, Haddad HA, Al-Yousef RM, El-Khateeb M, Abu-Rass H. Epstein-Barr virus and Hodgkin lymphoma in Jordan. Hematology/Oncology and Stem Cell Therapy , 2014 7: 85-89.

18. Glaser SL, Clarke CA, Chang ET, Yang J, Gomez SL, Keegan TH. Hodgkin lymphoma incidence in California Hispanics: Influence of nativity and tumor Epstein-Barr virus. Cancer Causes \& Control , 2014 25: 709-725.

19. Mani H, Jaffe ES. Hodgkin Lymphoma: An Update on its Biology with New Insights into Classification. Clinical Lymphoma and Myeloma, 2009 9: 206-216.

20. Chabay PA, Barros MHM, Hassan R, De Matteo E, Rey G, Carrico MK, Renault IZ, Preciado MV. Pediatric Hodgkin Lymphoma in 2 South American Series: A Distinctive Epidemiologic Pattern and Lack of Association of Epstein-Barr Virus With Clinical Outcome: Journal of Pediatric Hematology/Oncology , 2008 30: 285-291.

21. Lee J-H, Kim Y, Choi J-W, Kim Y-S. Prevalence and Prognostic Significance of Epstein-Barr Virus Infection in Classical Hodgkin's Lymphoma: A Meta-analysis. Archives of Medical Research , 2014 45: 417431.

22. Elsayed AA, Asano N, Ohshima K, Izutsu K, Kinoshita T, Nakamura S. Prognostic significance of CD20 expression and Epstein-Barr virus (EBV) association in classical Hodgkin lymphoma in Japan: A clinicopathologic study: CD20 expression \& EBV association in CHL. Pathol Int , 2014 64: 336-345.

23. Adamson P, Bray F, Costantini AS, Tao M-H, Weiderpass E, Roman E. Time trends in the registration of Hodgkin and non-Hodgkin lymphomas in Europe. European Journal of Cancer , 2007 43: 391-401.

24. Diepstra A, van Imhoff GW, Schaapveld M, Karim-Kos H, van den Berg A, Vellenga E, Poppema S. Latent Epstein-Barr Virus Infection of Tumor Cells in Classical Hodgkin's Lymphoma Predicts Adverse Outcome in Older Adult Patients. JCO , 2009 27: 3815-3821.

25. Hamdi L, Creidy R, Boudjemaa S, Hendel-Chavez H, Hugues P, Taoufik Y, Leblanc T, Coulomb A, Krzysiek R, Landman-Parker J, Besson C. Frequent altered distribution of peripheral B-lymphocyte subsets in pediatric and adolescent patients with classical Hodgkin lymphoma. Leukemia \& Lymphoma , 2020 1-8.

26. Jarrett RF, Krajewski AS, Angus B, Freeland J, Taylor PR, Taylor GM, Alexander FE. The Scotland and Newcastle epidemiological study of Hodgkin's disease: impact of histopathological review and EBV status on incidence estimates. J Clin Pathol, 2003 56: 811-816.

27. Glaser SL, Lin RJ, Stewart SL, Ambinder RF, Jarrett RF, Brousset P, Pallesen G, Gulley ML, Khan G, O'Grady J, Hummel M, Preciado MV, Knecht H, Chan JKC, Claviez A. Epstein-Barr virus-associated Hodgkin's disease: Epidemiologic characteristics in international data. International Journal of Cancer , 1997 70: $375-382$.

28. Takeuchi K, Morishita Y, Fukayama M, Mori S. Marked decrease in the Epstein-Barr virus positivity rate in nodular sclerosis subtype Hodgkin's disease in Tokyo: trend between 1955 and 1999. Br J Haematol , 2001 113: 429-431. 
29. Campos AHJFM, Moreira A, Ribeiro KB, Paes RP, Zerbini MC, Aldred V, de Souza CA, Neto CS, Soares FA, Vassallo J. Frequency of EBV associated classical Hodgkin lymphoma decreases over a 54-year period in a Brazilian population. Sci Rep , 2018 8: 1849.

30. Shannon-Lowe C, Rickinson AB, Bell AI. Epstein-Barr virus-associated lymphomas. Phil Trans R Soc B , 2017 372: 20160271.

31. Clavel J, Steliarova-Foucher E, Berger C, Danon S, Valerianova Z. Hodgkin's disease incidence and survival in European children and adolescents (1978-1997): Report from the Automated Cancer Information System project. European Journal of Cancer , 2006 42: 2037-2049.

32. Hjalgrim H, Askling J, Rostgaard K, Hamilton-Dutoit S, Frisch M, Zhang J-S, Madsen M, Rosdahl N, Konradsen HB, Storm HH, Melbye M. Characteristics of Hodgkin's Lymphoma after Infectious Mononucleosis. N Engl J Med , 2003 349: 1324-1332.

33. Hjalgrim H, Ekström Smedby K, Rostgaard K, Molin D, Hamilton-Dutoit S, Chang ET, Ralfkiaer E, Sundström C, Adami H-O, Glimelius B, Melbye M. Infectious Mononucleosis, Childhood Social Environment, and Risk of Hodgkin Lymphoma. Cancer Res , 2007 67: 2382-2388.

34. Glaser SL, Clarke CA, Keegan THM, Chang ET, Weisenburger DD. Time Trends in Rates of Hodgkin Lymphoma Histologic Subtypes: True Incidence Changes or Evolving Diagnostic Practice? Cancer Epidemiology Biomarkers \& Prevention, 2015 24: 1474-1488.

35. Solans M, Serra L, Renart G, Osca-Gelis G, Comas R, Vilardell L, Gallardo D, Marcos-Gragera R. Incidence and survival of Hodgkin lymphoma patients in Girona (Spain) over three decades: a populationbased study. European Journal of Cancer Prevention , 2017 26: S164-S169.

36. Küppers R, Rajewsky K. The origin of Hodgkin and Reed/Sternberg cells in Hodgkin's disease. Annu Rev Immunol , 1998 16: 471-493.

37. Carbone A, Gloghini A, Carlo-Stella C. Are EBV-related and EBV-unrelated Hodgkin lymphomas different with regard to susceptibility to checkpoint blockade? Blood , 2018 132: 17-22.

38. Uccini S, Al-Jadiry MF, Pepe G, Scarpino S, Al-Hadad SA, Ruco L. PD-L1 expression in pediatric Epstein-Barr virus positive classic Hodgkin lymphoma is not associated with 9p24.1 amplification. Pediatr Blood Cancer, 2019 66: e27757.

39. Green MR, Rodig S, Juszczynski P, Ouyang J, Sinha P, O’Donnell E, Neuberg D, Shipp MA. Constitutive AP-1 Activity and EBV Infection Induce PD-L1 in Hodgkin Lymphomas and Posttransplant Lymphoproliferative Disorders: Implications for Targeted Therapy. Clin Cancer Res , 2012 18: 1611-1618.

40. Fanale MA HS. Interim results from a phase 1 study of ADCT- 301 (camidanlumab tesirine) show promising activity of a novel pyrrolobenzodiazepine- based antibody drug conjugate in relapsed/ refractory Hodgkin/non-Hodgkin lymphoma. Blood , 2017.

\section{Figure legends}

FIGURE 1 Residual B follicles. 1a: HESx25, tumoral infiltrate surrounding a residual lymphoid follicle. 1b: CD20+ expression by residual B follicles. 1c: CD30+ tumor cells surrounding residual lymphoid follicle. 1d. EBV + tumor cells around residual lymphoid follicles, Eber in situ hybridation.

FIGURE 2 Overall survival depending on EBV status, in EBV cHL (red, $\mathrm{n}=68$ ) and non-EBV cHL (blue, $\mathrm{n}=233)$.

FIGURE 3 Event-free survival depending on EBV status, in EBV cHL (red, $\mathrm{n}=68$ ) and non-EBV cHL (blue, $\mathrm{n}=233$ ). 

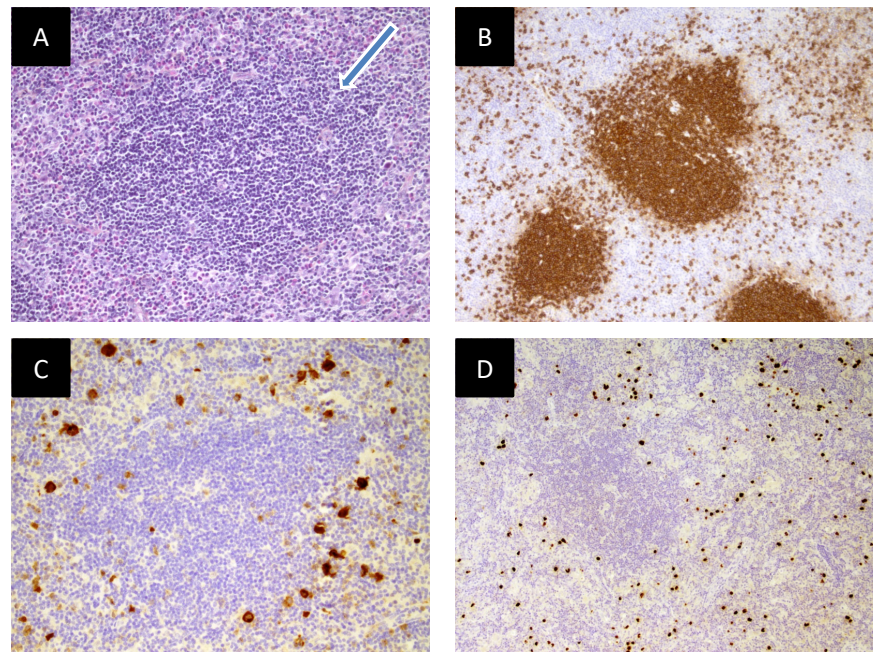

FIGURE 1 Residual B follicles. 1A: HESx25, tumoral infiltrate surrounding a residual lymphoid follicle. 1B:

CD20+ expression by residual B follicles. 1C: CD30+ tumor cells surrounding residual lymphoid follicle. 1D

$\mathrm{EBV}+$ tumor cells around residual lymphoid follicles, Eber in situ hybridation.
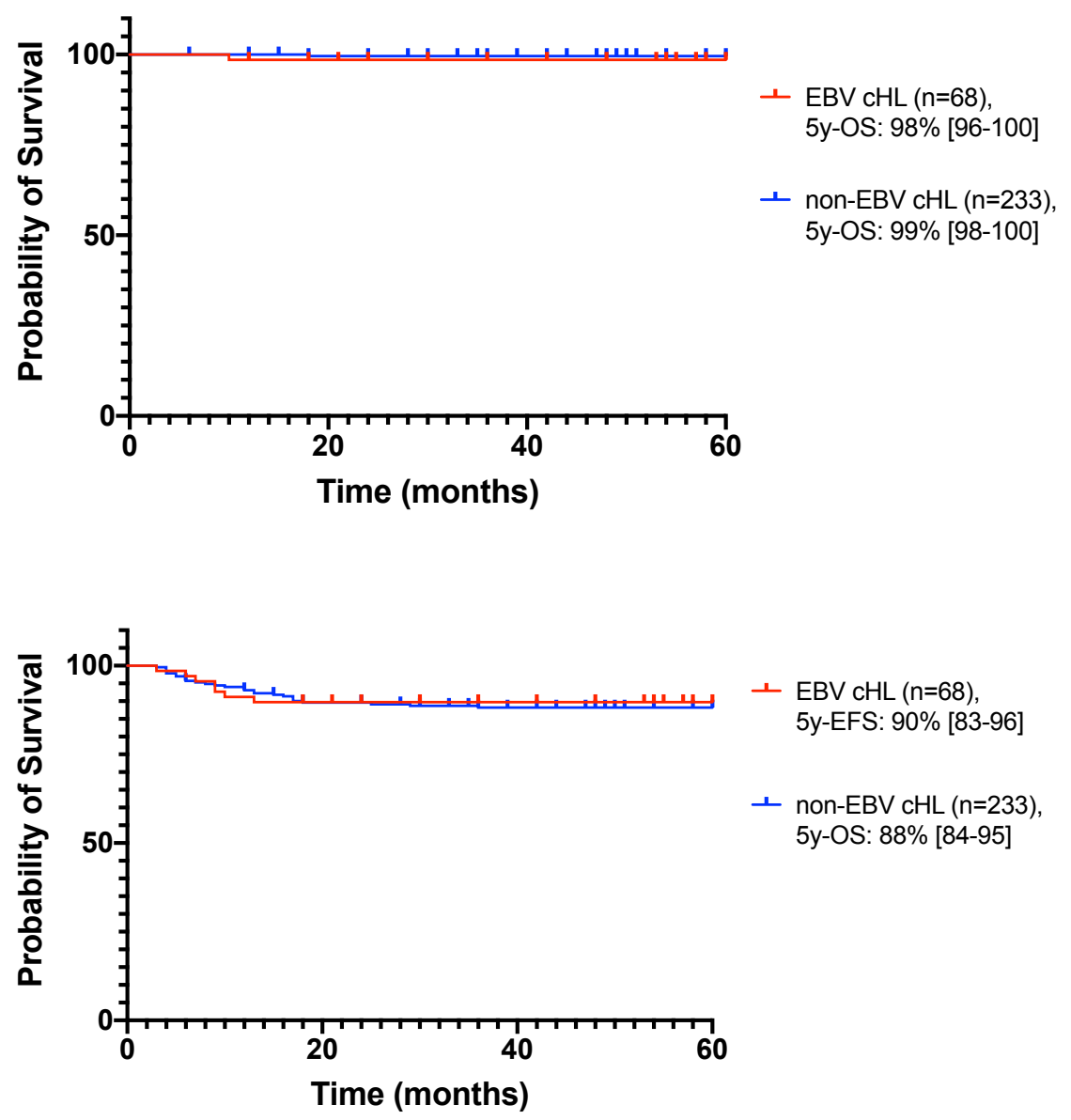


\section{Hosted file}

Table 1.docx available at https://authorea.com/users/415738/articles/523551-epstein-barrvirus-in-childhood-and-adolescent-classical-hodgkin-lymphoma-in-a-french-cohort-of-301patients

\section{Hosted file}

Table 2.docx available at https://authorea.com/users/415738/articles/523551-epstein-barrvirus-in-childhood-and-adolescent-classical-hodgkin-lymphoma-in-a-french-cohort-of-301patients

\section{Hosted file}

Table 3.docx available at https://authorea.com/users/415738/articles/523551-epstein-barrvirus-in-childhood-and-adolescent-classical-hodgkin-lymphoma-in-a-french-cohort-of-301patients 